\title{
Disease Gene Candidates Revealed by Expression Profiling of Retinal Ganglion Cell Development
}

\author{
Jack T. Wang, ${ }^{1 \star}$ Noelia J. Kunzevitzky, ${ }^{2 \star}$ Jason C. Dugas, ${ }^{1}$ Meghan Cameron, ${ }^{1}$ Ben A. Barres, ${ }^{1}$ and Jeffrey L. Goldberg ${ }^{1,2}$ \\ ${ }^{1}$ Department of Neurobiology, Stanford University School of Medicine, Stanford, California 94305, and ${ }^{2}$ Bascom Palmer Eye Institute and Graduate \\ Program in Molecular Cell and Developmental Biology, Miller School of Medicine, University of Miami, Miami, Florida 33136
}

To what extent do postmitotic neurons regulate gene expression during development or after injury? We took advantage of our ability to highly purify retinal ganglion cells (RGCs) to profile their pattern of gene expression at 13 ages from embryonic day 17 through postnatal day 21. We found that a large proportion of RGC genes are regulated dramatically throughout their postmitotic development, although the genes regulated through development in vivo generally are not regulated similarly by RGCs allowed to age in vitro. Interestingly, we found that genes regulated by developing RGCs are not generally correlated with genes regulated in RGCs stimulated to regenerate their axons. We unexpectedly found three genes associated with glaucoma, optineurin, cochlin, and CYP1B1 (cytochrome P450, family 1, subfamily B, polypeptide 1), previously thought to be primarily expressed in the trabecular meshwork, which are highly expressed by RGCs and regulated through their development. We also identified several other RGC genes that are encoded by loci linked to glaucoma. The expression of glaucoma-linked genes by RGCs suggests that, at least in some cases, RGCs may be directly involved in glaucoma pathogenesis rather than indirectly involved in response to increased intraocular pressure. Consistent with this hypothesis, we found that CYP1B1 overexpression potentiates RGC survival.

Key words: retinal ganglion cell; glaucoma; regeneration; axon; dendrite; microarray

\section{Introduction}

The molecular basis underlying the complex postmitotic development of a neuron is essentially unknown. For example, most rat retinal ganglion cells (RGCs) are born between embryonic day 13 (E13) and E18, extend their axons toward their targets between E14 and postnatal day 2 (P2), elaborate dendrites into the inner plexiform layer of the retina from E16, begin to receive synapses late embryonically, undergo a period of naturally occurring cell death between P2 and P5, and allow optic nerve oligodendrocytes to begin myelination after P7.

How much of the molecular control of the timing of these dynamic processes is attributable to developmental changes in gene expression of the neuron, either as the result of an intrinsic program or in response to signaling from its neighbors? In some cases, genes important for normal RGC development are expressed constitutively. For instance, as soon as they are generated by their precursor cells, RGCs express Eph receptors that are used 1-2 weeks later for topographic map formation in their targets in

\footnotetext{
Received 0ct. 14, 2006; revised June 11, 2007; accepted June 14, 2007.

This work was supported by National Institutes of Health Grants EY016790 and NS061348 (J.L.G.), EY11030 (B.A.B.), and P30 EY014801 (Miami, FL), the Glaucoma Research Foundation (J.L.G.), a Howard Hughes Medical Institute Medical Research Training Fellowship (J.T.W.), and an unrestricted grant from Research to Prevent Blindness (Miami, FL). We thank Lubert Stryer for generous advice, encouragement, and GeneChips; Cynthia Morton, Katalin Csiszar, and Sanjoy Bhattacharya for antibodies; and Janey Wiggs and Mansoor Sarfarazi for helpful discussions. We also thank Felix Vazquez-Chona and Eldon Geisert for making their gene profiling data available.

*J.T.W. and N.J.K. contributed equally to this work.

Correspondence should be addressed to Jeffrey L. Goldberg, Bascom Palmer Eye Institute, McKnight Vision Research Building, Room 405, 1638 NW 10th Avenue, Miami, FL 33136. E-mail: jgoldberg@med.miami.edu. DOI:10.1523/JNEUROSCI.4488-06.2007

Copyright $\odot 2007$ Society for Neuroscience $\quad$ 0270-6474/07/278593-11\$15.00/0
}

the superior colliculus and then continue to express these genes into adulthood (McLaughlin et al., 2003; Rodger et al., 2005). Other changes in RGC phenotypes may depend on developmental regulation of RGC gene expression. For example, RGCs undergo a developmental loss of their intrinsic capacity for rapid axon growth just after their axons reach their targets in the superior colliculus. Amacrine cells can signal embryonic RGCs to turn off their intrinsic capacity for axon growth, and this amacrine signal is dependent on new gene expression by RGCs (Goldberg et al., 2002).

To build new hypotheses for how dynamic RGC processes such as axon and dendrite growth, developmental cell death, synapse formation, and other neuron-glial interactions are timed and regulated, here we have characterized the RGC transcriptome throughout development. Gene expression profiling using microarrays and serial analysis of gene expression (SAGE) has been used previously to characterize gene changes occurring during development in various tissues or after injury, but the multiplicity of cell types in most tissues has in many cases limited the utility or interpretation of the data. For example, SAGE analysis of the mouse retina did not reveal any genes limited through development to RGCs, most likely because RGCs make up only $0.5 \%$ of the neurons in the retina (Blackshaw et al., 2004).

Here we take advantage of our ability to purify RGCs to homogeneity at different ages to better define the transcriptional changes that may account for the postmitotic differentiation program through RGC development. We found that the RGC transcriptome is surprisingly dynamic from E17 to P21. We identified changes in gene expression of as much as 100-fold that occur concurrently with major developmental events in the life of an 
RGC. We found that the gene changes accompanying normal RGC development are not mimicked by the gene changes that occur after RGC axotomy and attempted axon regeneration. Finally, we identified several genes linked to glaucoma that were unexpectedly highly expressed by RGCs and demonstrate that CYP1B1 (cytochrome $\mathrm{P} 450$, family 1 , subfamily $\mathrm{B}$, polypeptide 1) plays a role in RGC survival in vitro. The gene database we generated provides an invaluable new resource for generating testable hypotheses about how RGCs develop, why they fail to regenerate, and why RGCs die in glaucoma and other diseases.

\section{Materials and Methods}

Purification of retinal ganglion cells. RGCs from E17 through P21 Sprague Dawley rats were purified by sequential immunopanning to $99.5 \%$ purity and cultured on poly-D-lysine (PDL) (70 $\mathrm{kDa}, 10 \mu \mathrm{g} / \mathrm{ml}$; Sigma, St. Louis, MO) and lami$\operatorname{nin}(2 \mathrm{mg} / \mathrm{ml}$; Telios/Invitrogen, Carlsbad, CA) in serum-free defined medium as described containing BDNF (50 ng/ml), CNTF (10 ng/ $\mathrm{ml})$, insulin $(5 \mu \mathrm{g} / \mathrm{ml})$, and forskolin $(5 \mu \mathrm{M})$ (Barres et al., 1988; Meyer-Franke et al., 1995). Detailed protocols are available on request.

RNA preparation, microarray hybridization, and data analysis. RGCs from 13 different ages of Sprague Dawley rats were purified and allowed to recover for $1 \mathrm{~h}$ at $37^{\circ} \mathrm{C}$, after which total RNA was extracted using the RNeasy kit (Qiagen, Hilden, Germany). RNA quality was assessed by spectrophotometry and gel electrophoresis. Total RNA $(1 \mu \mathrm{g})$ was reverse transcribed into cDNA, amplified once by in vitro transcription, reverse transcribed into cDNA, and then used to generate biotinlabeled cRNA, according to the protocols of Affymetrix (Santa Clara, CA). Fragmented cRNA was hybridized onto rat genome U34A, U34B, and U34C arrays (Affymetrix) containing 26,000 probes against $\sim 13,000$ genes. Scanned output files were analyzed with Microarray Suite 5.0 (Affymetrix) as well as by ANOVA and normalized to an average intensity of 1500. Subsequent analysis using Microarray Suite 5.0, Excel (Microsoft, Seattle, WA), and SAS 8.0 (SAS Institute, Cary, NC) for ANOVA confirmation of statistical reproducibility is described in Results. Time course data for all probes are available on-line (supplemental Table 1, available at www.jneurosci.org as supplemental material).

Quantitative real-time reverse transcription-PCR. Total RNA was extracted from purified E20 and P8 RGCs as described above, of which $1 \mu \mathrm{g}$ was reversed transcribed into cDNA (iScript; Bio-Rad, Hercules, CA). Equal amounts of cDNA were further amplified by real time-PCR (iQ SYBR Green supermix; Bio-Rad). We used 18 S ribosomal RNA as an internal reference. Primers used were as follows: matrix Gla protein (Mgp) forward, GCCCTGATCTACGGGTACAA; Mgp reverse, GAACAAGCAACGAACACGAA; connective tissue growth factor (Ctgf) forward, CAGGGAGTAAGGGACACGAA; Ctgf reverse, TCCCACAGCAGTTAGGAACC; Gp46 forward, GGTACTGCGGAGAAGCTGAG; Gp46 reverse, CCAAGGGTGACAGGAGGATA; 18 S forward, GAACTGAGGCCATGATTAAGAG; and 18S reverse, CATTCTTGGCAAATGCTTTC. Reactions were run with five replicates per primer pair, and repeated at least three times on different days.

Western blotting and immunofluorescence. Western blotting was performed using standard protocols. Approximately $15 \mu \mathrm{g}$ of acutely isolated E20 and P8 RGC cell lysates collected in radioimmunoprecipitation assay buffer were transferred to $0.45 \mu \mathrm{m}$ nitrocellulose (Bio-Rad) and incubated overnight at $4^{\circ} \mathrm{C}$ in rabbit anti-CYP1B1 antiserum $(3 \mu \mathrm{g} / \mathrm{ml}$; Alpha Diagnostics, San Antonio, TX), rabbit anti-optineutin antiserum

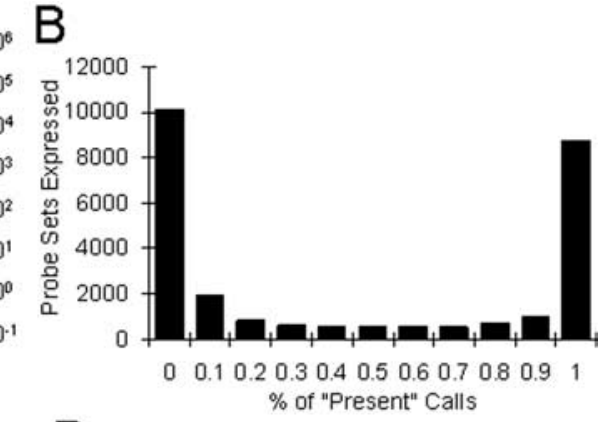

D

Expression, Retina
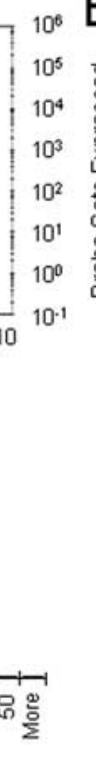

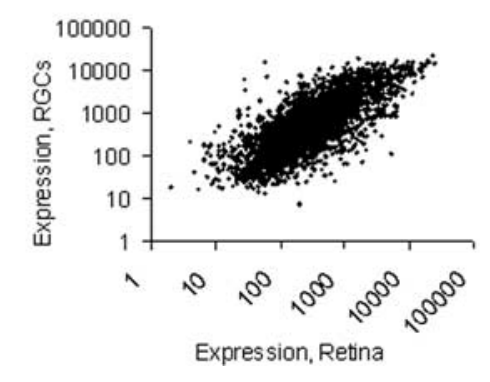

Figure 1. Gene expression of RGCs through development. $\boldsymbol{A}$, Reproducibility of samples. Two biological replicate samples of
E17 RGCs are plotted against each other, with 2-, 3-, 5-, and 10-fold difference bars included. $\boldsymbol{B}$, Number of genes expressed in $\mathrm{RGC}$, as defined by present calls in Microarray Suite 5.0 (Affymetrix), plotted as a histogram. $\boldsymbol{C}$, Of the probes present in at least $10 \%$ of RGC samples through development, the number of probe sets that change through RGC development from E17 to P21, plotted as a histogram. D, P21 RGC versus adult whole retinal gene expression, plotting only the genes from U34A GeneChips found present in the RGC samples. Tenfold difference lines are plotted.

( $5 \mu \mathrm{g} / \mathrm{ml}$; Caymen Chemical, Ann Harbor, MI), or chicken anti-cochlin antiserum (1:500) (Robertson et al., 2001), followed by $2 \mathrm{~h}$ with antirabbit or anti-chicken horseradish peroxidase secondary antibody (1: 10,000; Millipore, Billerica, MA). All incubation was performed in 5\% milk. Detection was performed using ECL (GE Healthcare, Little Chalfont, UK).

For immunostaining of retina, retinal tissues were dissected from freshly killed E20, P8, and adult (P21) Sprague Dawley rats and immediately fixed in $4 \%$ paraformaldehyde for $1 \mathrm{~h}$. The tissues were cryoprotected in $30 \%$ sucrose, snap frozen in mounting medium (OCT, TissueTek; Miles, Elkhart, IN), and 8-12 $\mu \mathrm{m}$ sections were cut and mounted on aminoalkylsilane-coated slides (Sigma). Sections were postfixed in $4 \%$ paraformaldehyde for $10 \mathrm{~min}$ and then blocked and permeabilized with $20 \%$ goat serum and $0.4 \%$ Triton X-100 for $30 \mathrm{~min}$. Retinal tissues were incubated with anti-lysyl oxidase (1:100; generous gift from $\mathrm{K}$. Csiszar, University of Hawaii, Honolulu, HI) and the same anti-CYP1B1, antioptineurin, or anti-cochlin antibody as described above at $5 \mu \mathrm{g} / \mathrm{ml}, 10$ $\mu \mathrm{g} / \mathrm{ml}$, and 1:1000 dilutions, respectively. Secondary detection was performed with fluorescence antibodies (1:500 dilution; Millipore) using anti-rabbit (for CYP1B1, optineurin, and lysyl oxidase) or anti-chicken antibody (for cochlin). The slides were mounted in Vectashield with $4^{\prime}, 6^{\prime}$-diamidino-2-phenylindole, sealed with nail polish, and examined in a Nikon (Tokyo, Japan) Diaphot fluorescence microscope.

For immunoreactivity of RGCs, E20 and P8 RGCs were purified and cultured on laminin-coated glass coverslips in serum-free growth media for $24 \mathrm{~h}$. Cultures were maintained at $37^{\circ} \mathrm{C}$ in a humidified environment of $10 \% \mathrm{CO}_{2} / 90 \% \mathrm{O}_{2}$. Cell fixation, membrane permeabilization, and antibody incubation were performed as above.

Analysis of human glaucoma genes. We identified glaucoma loci at the National Center for Biotechnology and Information Online Mendelian Inheritance in Man Database (http://www.ncbi.nlm.nih.gov/entrez/ query.fcgi? $\mathrm{CMD}=$ search $\& \mathrm{DB}=$ omim). For each glaucoma locus, we generated a list of candidate genes encoded between the human genomic linkage analysis markers described in the appropriate reference. Using Netaffx Analysis Center (Affymetrix), we determined whether these genes were expressed by at least $10 \%$ of RGC samples in the microarray 
Table 1. Genes expressed at least $\mathbf{2 0}$-fold higher in P21 RGCs than in adult retina

\begin{tabular}{|c|c|c|c|}
\hline Gene symbol & Description & Fold change RGCs/retina & References \\
\hline & Similar to Homo sapiens neuroblastoma cDNA (clone Nbla00127) & 261.07 & \\
\hline Nell2 & NEL-like 2 homolog (chicken) & $224.48^{e}$ & Nelson et al., 2002 \\
\hline Nell1 & NEL-like 1 (chicken) & 124.36 & \\
\hline$a$ & Mus musculus hypothetical LOC434481 & 122.94 & \\
\hline Tspan8 & Tetraspanin 8 & 53.02 & \\
\hline Lsamp & Limbic system-associated membrane protein & $52.25^{b}$ & Lodge et al., 2000 \\
\hline Rab3c & RAB3C, member RAS oncogene family & $45.52^{c}$ & Grabs et al., 1996 \\
\hline Hspb1 & Heat shock 27 kDa protein 1 & $42.29^{d}$ & Krueger-Naug et al., 2002; Whitlock et al., 2005 \\
\hline \multirow[t]{2}{*}{ LOC498335 } & Similar to small inducible cytokine B13 precursor (CXCL13) & 41.71 & \\
\hline & Mus musculus RIKEN cDNA clone (IMAGE 40094663) & 40.58 & \\
\hline$a$ & Mus musculus similar to rRNA promoter binding protein & 40.40 & \\
\hline $\operatorname{Sen} 3 a$ & Sodium channel, voltage-gated, type III, $\alpha$ polypeptide & $38.16^{c}$ & Kawai et al., 2005 \\
\hline RGD1561067 ${ }^{a}$ & Similar to RNA-binding protein gene & 37.97 & \\
\hline RGD1562317 & Similar to expressed sequence AW212394 & 36.53 & \\
\hline Plcb1 & Phospholipase C, $\beta 1$ & 32.27 & Lee et al., 1993 \\
\hline Adcyap1 & Adenylate cyclase activating polypeptide 1 & $29.08^{b}$ & Izumi et al., 2000; Sakamoto et al., 2004 \\
\hline Pkib & Protein kinase inhibitor $\beta$, cAMP dependent, catalytic & 27.40 & \\
\hline Spock $2^{a}$ & Sparc/osteonectin, cwcv, and kazal-like domains & 27.36 & \\
\hline Inexa & Internexin, $\alpha$ & $26.82^{e}$ & Chien and Liem, 1995 \\
\hline $\mathrm{RGD1561067^{a }}$ & Similar to RNA binding protein gene & 26.33 & \\
\hline $\operatorname{lgf1}$ & Insulin-like growth factor 1 & $23.16^{b}$ & Lee et al., 1992; Bergman et al., 2005 \\
\hline Prph1 & Peripherin 1 & $22.84^{e}$ & Escurat et al., 1990 \\
\hline Capon & C-terminal PDZ domain ligand of neuronal nitric oxide synthase & 21.36 & Park et al., 1996 \\
\hline Nef3 & Neurofilament 3 , medium & $21.32^{e}$ & Rhee et al., 2004; Ruiz-Ederra et al., 2004 \\
\hline Gap43 & Growth-associated protein 43 & $21.14^{b}$ & Capone et al., 1991; Ekstrom and Johansson, 2003 \\
\hline Nupl1 & Nucleoporin-like 1 & 20.78 & \\
\hline Egr4 & Early growth response 4 & 20.51 & \\
\hline
\end{tabular}

apredicted. In reference(s) given.

${ }^{b}$ Not RGC specific.

Not found in retina.

${ }^{d}$ Induced in RGCs after injury.

${ }^{e}$ May be RGC specific at specific developmental stages.

data and then further identified the subset of genes that change more than threefold during development (E17 to P21).

$R G C$ transfection and survival assay. Full-length cDNA constructs for mouse CYP1B1 (clone ID 30007248), cochlin (clone ID 6306601), and rat optineurin (clone ID 7111026) (all from Openbiosystems, Huntsville, $\mathrm{AL}$ ) were verified by sequencing and amplified by Maxi-preps (Qiagen). Small interference RNA (siRNA) for rat CYP1B1 (catalog number L-087731-00; Dharmacon, Lafayette, CO) concentration and quality were assessed by spectrophotometry. Transfection of cDNA or siRNA constructs into RGCs was achieved using Nucleofector for primary neurons ("G13" setting; Amaxa, Gaithersburg, MD). Briefly, $\sim 3.5 \times 10^{5}$ purified RGCs were electroporated, allowed to recover at $37^{\circ} \mathrm{C}$ for $1 \mathrm{~h}$, and subsequently cultured on PDL- and laminin-coated six-well plates for $72 \mathrm{~h}$. Transfection efficiency was separately measured with a supplied control pmaxGFP or mCherry plasmid.

Survival was determined by treatment of RGCs with a mammalian live/dead cell assay kit containing calcein AM and ethidium homodimer (Invitrogen), fluorescent indicators of metabolically active and membrane-permeant cells, respectively, for $30 \mathrm{~min}$, after which the cells were counted in 10 random, independent fields by an investigator masked to each condition on an inverted fluorescent microscope at $20 \times$. A two-proportion $Z$ test between experimental and control conditions was used to test for significance.

\section{Results}

\section{Retinal ganglion cell gene expression}

RGCs were purified to homogeneity by immunopanning from 13 ages: E17, E18, E19, E20, E21, P0, P1, P2, P5, P8, P11, P16, and $\mathrm{P} 21$. Three to four biological replicates were prepared from each age and processed independently for microarray analysis using Affymetrix U34A-U34C rat genome arrays. Intersample variability was very low, with a Pearson's correlation coefficient of $r^{2} \geq$
0.90 for same-age samples (Fig. $1 A$ ); comparing E17 to P21 samples, in contrast, yielded $r^{2}$ values of $\sim 0.1-0.2$.

Using the algorithm in Microarray Suite 5.0 to determine whether probed genes were "absent" or "present," we found that $33 \%$ of probed genes were expressed in RGCs throughout the entire time course, an additional $29 \%$ were expressed in a subset of time course samples, and $38 \%$ were not detected in RGCs at all (Fig. $1 B$ ). We found in these data that probes began to be called present at signal strengths $\sim 1000$ (arbitrary units) (supplemental Fig. 1, available at www.jneurosci.org as supplemental material), although signal strength was not a criterion we used to filter the data further. We analyzed only those 14,166 probes that the Affymetrix Microarray Suite 5.0 algorithm called present in at least $10 \%$ of the RGC samples from here forward, making sure that probes were also reproducibly present in RGC samples of at least one age. We found a remarkable number changed in their levels of expression through development: 3621 probes $(26 \%)$ changed at least threefold, $474(3.3 \%)$ changed at least 10 -fold, and $175(1.3 \%)$ changed at least 20-fold (Fig. 1C) (supplemental Table 2, available at www.jneurosci.org as supplemental material). We compared the top changers in RGCs with the top changers published for striatal (Lobo et al., 2006) and cortical (Arlotta et al., 2005) projection neurons and found that each population developmentally regulates very different genes. Of the 35 reported genes developmentally regulated between P20 and adult striatal neurons, only three were found in our data to be developmentally regulated in RGCs between E20 and P21 (heat shock $70 \mathrm{kDa}$ protein $1 \mathrm{~A}$, ryanodine receptor 2 , and 
calbindin 1). Similarly, of the 27 reported genes between E18 and P14 in corticospinal motor neurons that were found in the RGC GeneChip dataset, only two were developmentally regulated in RGCs (Purkinje cell protein 4 and neurofilament-H). We also compared P21 RGC gene expression with adult retinal gene expression published previously (Vazquez-Chona et al., 2004) using triplicate biological samples and data from the Affymetrix U34A GeneChips ( $~ 8800$ probes $)$. Of the 3566 genes present in at least two of three P21 RGC samples, most were also observed in retina (Fig. $1 D$ ). We identified 28 genes at least 20-fold more highly expressed in RGCs compared with total retina by microarray analysis (Table 1 ) and 1016 genes at least threefold greater in RGCs compared with total retina, although many of these may not be good candidates for RGC-specific genes.

To classify RGC gene expression further, we analyzed the 8557 probes annotated by gene ontology and fit 6612 of them into 27 partially overlapping categories. We found that RGCs expressed between 39 and $80 \%$ of the probes in these gene ontology categories (Table 2). There was not a statistically significant difference in the likelihood of expressing a greater or lesser percentage of genes in any one category. We then examined what gene ontologies were most likely to contain genes that change at least threefold across RGC development (Table 2) and found statistically significant differences in the fractions of genes changing in different categories. Specifically, several ontologies were less likely to contain genes that changed through RGC development, including mitochondrion/mitochondrial (15\%), nicotinamide adenine dinucleotide (nadh)/nadph (8\%), proteasome $(0 \%)$, RNA (19\%), and ubiquitin (13\%), and two stood out as more likely to contain developmentally regulated genes, neurotransmitter (50\%) and synapse/synaptic (42\%). Thus, protein functions relating to energy metabolism and protein degradation pathways remained fairly constant through the postmitotic maturation of RGCs, whereas synaptic communication played the most dramatic role in developmental changes in RGC gene expression.

We were interested in a cluster of genes related to extracellular matrix and chose to validate the gene expression data from the microarrays by quantitative real-time reverse transcription (RT)PCR and immunostaining. We confirmed that Mgp, Ctgf, and the collagen-binding protein Gp46 change in the same direction in the GeneChip as by quantitative real-time RT-PCR (Fig. 2A), and we found a developmentally regulated increase in lysyl oxidase protein expression in vivo and in vitro by immunostaining (Fig. $2 B$ ). As others have found, the scale of fold change by microarray and by real-time RT-PCR was often different, although the direction of fold change was always the same. These data, together with the immunostaining and Western blotting for glaucoma-related genes presented below (see Fig. 6), help validate the microarray data.

\section{Clustering by samples and by genes}

We next asked at what age(s) do RGCs undergo their greatest changes in gene expression? We applied non-negative matrix factorization (NMF) to cluster RGC samples into age ranges (Brunet et al., 2004). First, the samples clustered remarkably well by age, suggesting that biological variability was greater between than within age group samples. A two-cluster solution split 42 RGC samples exactly at the border between P2 and P5, a three-cluster solution split RGC development at E21 and P5, and four- and five-cluster solutions added additional splits between E19 and P16 with a maximum of 5 of 42 samples realigned for consistency (Fig. 3). Although we had an interest in the developmental loss of axon growth ability that occurs at P0 (Goldberg et al., 2002), it is apparent from these data that many of the gene changes during development may be associated with other biological processes, such as synaptogenesis and neurotransmission. Thus, RGCs appear to undergo their most dramatic change in overall gene expression at P2, and these data furthermore suggest that the developmental age of an RGC may be reliably determined by its gene expression profile.

We used hierarchical clustering to ask whether there were repeated patterns of RGC gene expression regulation throughout the time course. Probes expressed in a minimum of $10 \%$ of samples and exhibiting a fold change more than three were analyzed using the Affymetrix Database Mining Tool. A four-cluster solution yielded a group of genes that decreased in expression through development, two groups that increased through development, and an interesting group that spiked in the period around birth (Fig. 4) (supplemental Table 3, available at www. jneurosci.org as supplemental material). Clustering solutions al- 

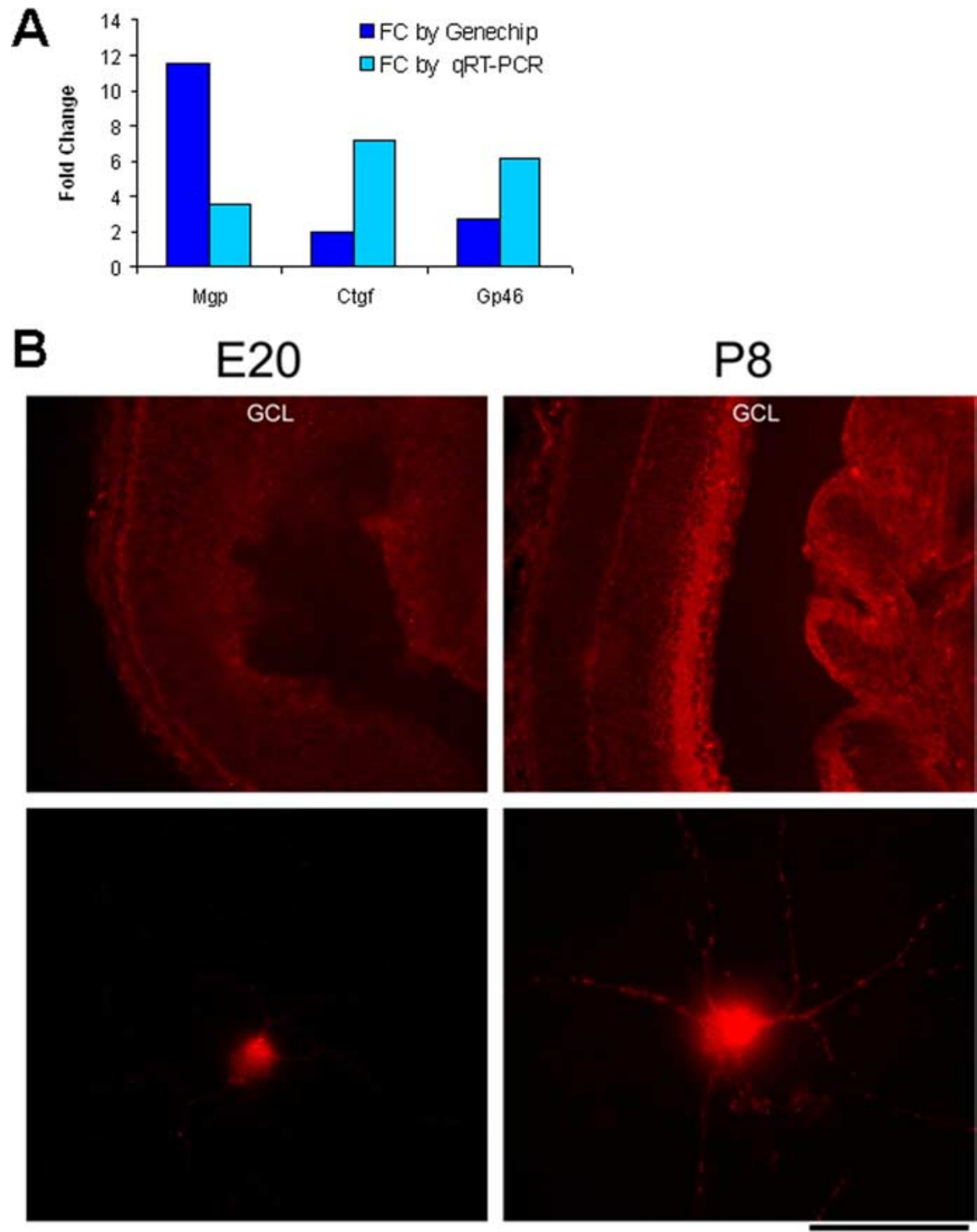

Figure 2. Validation of microarray data. $A$, Comparison of fold changes $(\mathrm{FC})$ in gene expression during RGC development by GeneChip (average of at least 3 samples) and real-time RT-PCR (average of 5 samples; 1 representative of 3 separate data replications are shown). $\boldsymbol{B}$, Lysyl oxidase protein is upregulated in rat retinal cryosections in P8 RGCs compared with E20 retinal sections in the ganglion cell layer (GCL) and the adjacent inner plexiform layer in which RGC dendrites are located (top row). A similar upregulation is seen from E20 to P8 RGC cultures (bottom row). Scale bar: top row, $450 \mu \mathrm{m}$; bottom row, $50 \mu \mathrm{m}$.

lowing more than four clusters yielded subclusters primarily derivative of the two patterns shown in Figure $4, A$ and $B$.

\section{Intrinsic aging versus extrinsic regulation of RGC gene expression}

We next asked whether RGCs regulate their gene expression similarly in vivo and ex vivo in purified cultures. We purified P7-P8 RGCs and aged them in growth media for 8-10 d in vitro, to the age they would have been $\mathrm{P} 16$ in vivo. We then compared these aged RGCs with acutely purified P8 and P16 RGC using GeneChips, analyzing triplicate or quadruplicate biological replicates for each of these three groups. Of 26,256 probes, the MicroArray Suite (Affymetrix) algorithm detected $14,942(57 \%)$ as present in at least one biological sample. We found that 941 of 14,942 probes $(6.3 \%)$ changed at least threefold between acutely purified P8 and P16 RGCs (aged "in vivo") or between acutely purified P8 RGCs and P8 RGCs aged in vitro. Of these 941 probes, only 96 (10.2\%) changed coor- dinately in RGCs aged in vitro versus in vivo, whereas 168 probes changed only in vivo, 666 changed only in vitro, and 11 changed in opposite directions in the two conditions. Thus, at least by analysis of gene expression profiles, RGCs aged in vitro do not closely mimic RGCs aged in vivo, although it is possible that placing the cells in culture interfered with a cell-autonomous progression in gene expression that RGCs were expressing in vivo. This suggests that many of the postmitotic changes in RGC expression are dependent on signals from the environment in vivo not found in cell culture.

\section{Expression of genes regulated both during development and after regeneration}

RGCs normally fail completely to regenerate after axon injury in the optic nerve, but a small subset of RGC axons can be induced to reextend past the injury site in response to lens injury, which recruits macrophages and elicits release of a novel trophic factor for RGCs (Fischer et al., 2000; Leon et al., 2000; Yin et al., 2003, 2006; Fischer et al., 2004). By fluorescence-activated cell sorting retrogradely labeled RGCs, the genes regulated by lens injury after axotomy were compared with those regulated by axotomy alone using microarray analysis (Fischer et al., 2004). We asked whether any of the 73 identified genes regulated at least threefold after axotomy plus lens injury were also regulated during RGC development. Sixty genes were represented in our dataset, of which 46 (77\%) were expressed by developing RGCs, and 34 (74\% of those expressed) demonstrated at least a threefold developmental regulation of expression between E17 and P21 (Fig. 5A). We divided these 34 genes into four groups according to whether they were upregulated or downregulated in each dataset (Fig. 5B). Because RGCs decrease their axon growth ability during development, we hypothesize that genes that are developmentally downregulated could be stimulatory for axon growth; 10 of 13 of these are upregulated after axotomy with lens injury (Fig. 5). Conversely, we hypothesize that genes that are developmentally upregulated may be inhibiting RGC axon growth; 12 of 21 of these are downregulated after axotomy with lens injury. A caveat to this analysis is that the previous data did not identify genes expressed in the subset of RGCs that successfully regenerated into the optic nerve, but rather the genes expressed in all RGCs under conditions that stimulate a subset to regenerate (Fischer et al., 2004). Thus, 22 (65\%) of 34 genes regulated during development and after axotomy plus lens injury are regulated inversely in these two conditions and may be critical candidates when exploring the link between developmental and regenerative axon growth. 
Expression of glaucoma candidate genes by RGCs

We unexpectedly identified RGC expression of three genes, CYP1B1, optineurin, and cochlin, in which mutations are associated with glaucoma (Stoilov et al., 1997; Rezaie et al., 2002; Bhattacharya et al., 2005). We found that optineurin and cochlin mRNA were upregulated during development (1.86- and 15.2-fold, respectively), and CYP1B1 mRNA was downregulated (27.1-fold) through this time course (Fig. $6 A$ ).

Immunostaining for these three proteins in the neural retina all showed significant staining in the RGC layer (Fig. 6B). Bright, punctuate staining of RGCs was most prominent for CYP1B1 in embryonic retina and for optineurin in postnatal retina. For cochlin and CYP1B1, immunoreactivity was also intense in the pigmented retinal epithelium, consistent with previous immunolocalization studies in the eye (Bhattacharya et al., 2005; Doshi et al., 2006).

We confirmed RGC expression of these three proteins by Western blot on protein lysates from purified RGCs (Fig. 6C). A doublet band was observed at 80 and $65 \mathrm{kDa}$ for CYP1B1, with higher protein expression seen in embryonic RGCs. A doublet band was observed at 40 and $60 \mathrm{kDa}$ for optineurin, with higher protein expression in postnatal RGCs. For cochlin, a single band of $\sim 60 \mathrm{kDa}$ was observed, with slightly higher protein expression in postnatal RGCs. Similarly, in purified RGCs, immunostaining showed predominantly cytoplasmic localization for CYP1B1 in embryonic and postnatal RGCs. Cochlin and optineurin demonstrated a more diffuse localization but with increasing cytoplasmic staining for both proteins in postnatal RGCs (Fig. 6D). These data further confirmed the developmental upregulation of cochlin and optineurin and the developmental downregulation of CYP1B1 expression in RGCs, consistent with the respective change of mRNA levels observed in the microarray data.

At least 13 other human genomic loci have been associated with glaucomatous disease by linkage analyses, although the causative genes in these loci are not known. We hypothesized that RGCs may express a subset of genes from these loci and found that, of the 1590 genes expressed in these 13 genomic loci, probes were identifiable in our database for 479 rat homologs. Of these 479 genes, RGCs expressed 343 (72\%), and, of these, 109 (32\%) were developmentally regulated at least threefold (supplemental Table 4, available at www.jneurosci.org as supplemental material). A subset of these is known to be associated with apoptosis by gene ontology designation (supplemental Table 5, available at www.jneurosci.org as supplemental material); many have as yet unknown functions.

\section{Effect of glaucoma-associated genes on RGC survival}

That RGCs highly express and developmentally regulate several candidate glaucoma genes suggests that some of these genes may function cell autonomously in normal or diseased states. One such function may be to directly influence RGC survival. To test this hypothesis, we overexpressed these three candidate genes in
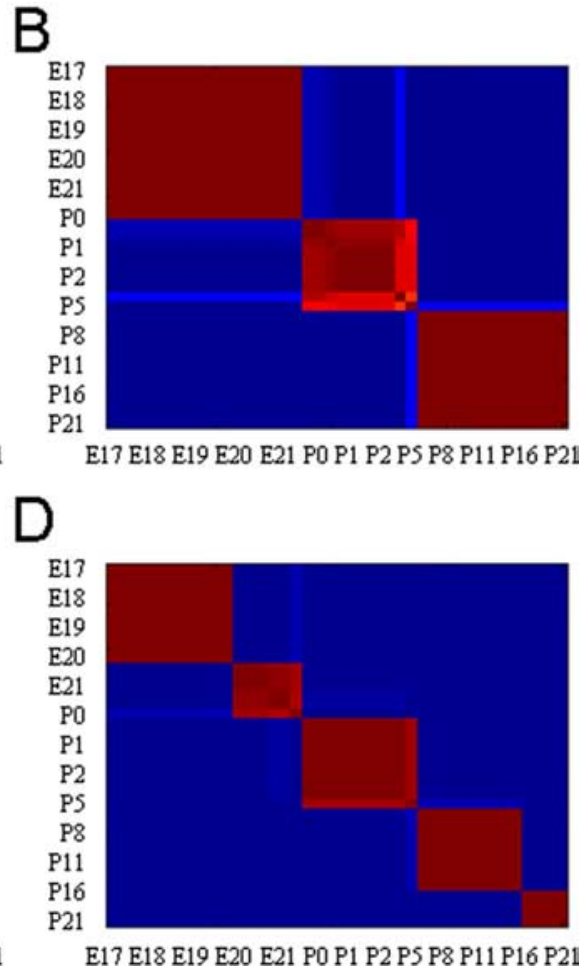

E17 E18 E19 E20 E21 P0 P1 P2 P5 P8 P11 P16 P2

Figure 3. Non-negative matrix factorization. Datasets were weaned to include only genes present in at least $10 \%$ of RGC samples and changing at least threefold through development, analyzed by NMF, and internally sorted to amplify boundary edges. The axes demonstrate the ages of the RGC samples analyzed.

both postnatal and embryonic RGCs using electroporation. There was no consistent effect of overexpression of optineurin or cochlin in these experiments (Fig. $7 A, B$ ). We found that overexpression of CYP1B1, however, modestly but significantly improved survival in both embryonic and postnatal RGCs (Fig. $7 \mathrm{~A}, \mathrm{~B})$. The effect was slightly stronger in postnatal RGCs, which express lower levels of CYP1B1 endogenously in vivo and in vitro (Fig. 6). CYP1B1 encodes a mono-oxygenase of the P450 superfamily and catalyzes the rate-limiting step in retinoic acid (RA) synthesis. It is possible that RA may either augment or be a neuroprotective effector of CYP1B1. To test the relationship between RA and CYP1B1 on RGC survival, we transfected CYP1B1 into cultured RGCs in various RA concentrations. We found that, at $10 \mu \mathrm{M}$ retinoic acid or above, survival was modestly improved in CYP1B1-transfected RGCs for both E20 and P8 RGCs compared with control RGCs (data not shown).

We next asked whether gene knockdown of CYP1B1 by siRNA would have the opposite effect on embryonic RGC survival. We found that CYP1B1 but not control siRNA decreased embryonic RGC survival (Fig. 7C). We further cotransfected the plasmids with a mCherry reporter construct to confirm successful transfection and to determine the percentage of live cells that are overexpressing our plasmids of interest. We found that there is a significantly greater portion of surviving postnatal RGCs that overexpress CYP1B1 than siRNA-CYP1B1 or the reporter construct alone. Thus, our results suggest that CYP1B1 overexpression promotes RGC survival in vitro and that it may normally be neuroprotective in RGCs.

\section{Discussion}

The postmitotic RGC transcriptome is highly dynamic

By purifying RGCs, which normally represent fewer than $0.5 \%$ of the cells in the retina, we found we could characterize RGC gene 
A

\section{Chuster 1 - Decrease Perinatally}

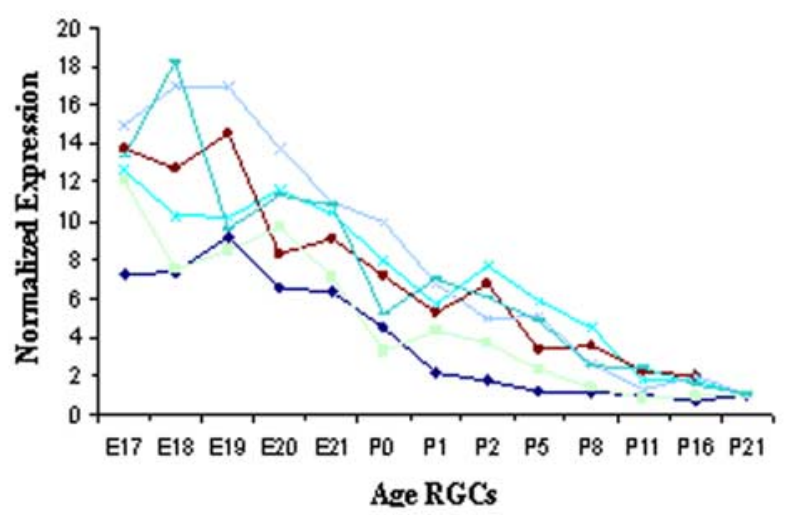

B

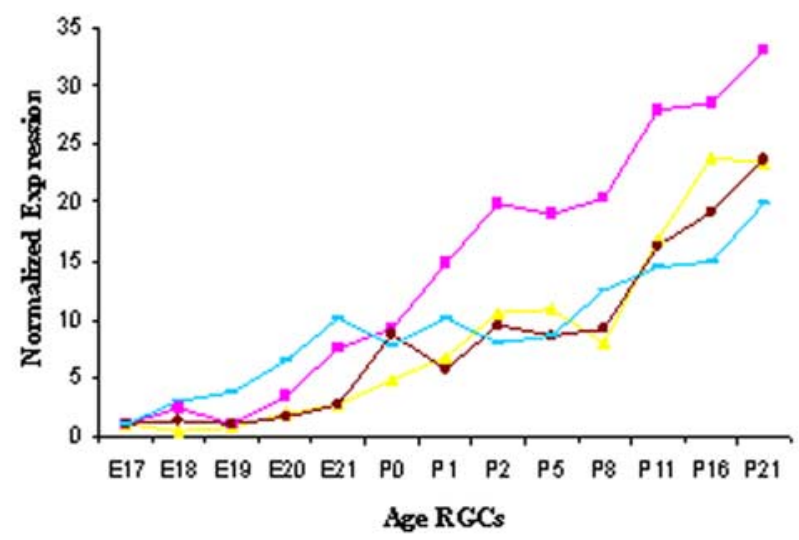

Cluster 3 - Spike Permatally

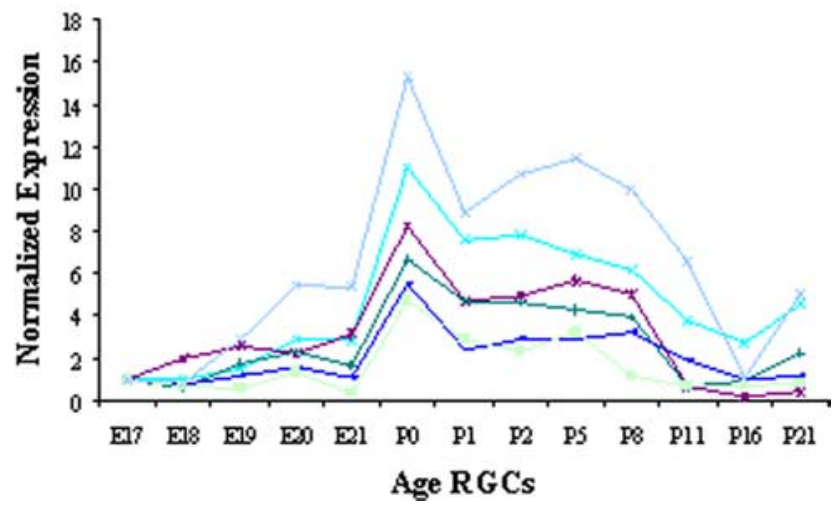

Figure 4. Hierarchical cluster analysis limited to four clusters revealed one cluster of genes that decreased perinatally, two clusters of genes that increased perinatally (only 1 is shown here), and a cluster of genes that spiked at birth and then returned to lower levels after the first postnatal week. Each graph shows the normalized expression levels through development of the highest fold-changing individual genes. Probes from these clusters are listed in supplemental Table 3 (available at www.jneurosci.org as supplemental material).

expression through development from E17 to P21. These data greatly extend the single time point snapshots of gene expression we and others have published previously for RGCs (Farkas et al., 2004; Fischer et al., 2004; Ivanov et al., 2006) and allowed comparison with development surveys of gene expression in other CNS neurons, including striatal (Lobo et al., 2006) and cortical (Arlotta et al., 2005) projection neurons. Interestingly, it appears that the genes that are developmentally regulated in each of these three populations are almost entirely different. As seen in these two previous papers, the ability to survey RGC transcripts without the $>100$-fold dilution of other retinal cells present likely allowed an increased sensitivity and specificity for detecting RGC gene expression and generated candidate genes that are highly enriched in RGCs and may yield RGC-specific markers. A caveat to these data are the comparison of young adult (P21) RGCs to adult retinas, and RGC gene expression appears likely to change between these time points based on the dramatic changes seen through the rest of RGC development. Whether these genes are also present in adult RGCs remains to be elucidated.

Although these neurons are postmitotic, their transcriptome proved highly dynamic through development, with $26 \%$ of genes changing expression level at least threefold through this period and $>3 \%$ changing at least 10 -fold. Interestingly, we found that developmental changes in RGC gene expression are primarily dependent on environmental signals, whereas RGCs were able to regulate relatively few of the same genes by aging in vitro in purified cultures. Thus, the postmitotic transcriptome is highly dynamic and appears to be highly dependent on neighboring cells. By coculturing RGCs with other purified populations of CNS neurons and glia from the retina, optic nerve, and targets in the brain, we may discover which cell types are responsible for regulating at least a subset of RGC gene expression changes.

\section{RGCs express glaucoma candidate genes}

This study identified RGC expression of optineurin, in which mutations have been identified in a subset of familial primary open-angle glaucoma (POAG) patients with linkage to the GLC1E locus (Rezaie et al., 2002). Our findings that optineurin mRNA and protein expression increase through RGC development is consistent with previous reports of optineurin protein expression in adult mouse RGCs (Rezaie and Sarfarazi, 2005; De Marco et al., 2006). Optineurin binds to Huntingtin (Faber et al., 1998 ), a protein with a recently discovered role in axonal BDNF transport and survival signaling (Gauthier et al., 2004). In addition, in cell lines, optineurin translocates to the nucleus in response to proapoptotic oxidative stress, and overexpression of the wild-type but not a mutated transcript is protective in these assays (De Marco et al., 2006). Thus, loss of normal optineurin function may lead to attenuated axonal trophic transport in RGCs and secondary neuronal degeneration, consistent with the characteristic axon loss seen in glaucoma.

Our data also revealed RGC expression of cochlin, a gene whose protein deposits were found in higher levels in the trabecular meshwork (TM) of POAG patients and glaucomatous DBA/2J mice (Bhattacharya et al., 2005). Mutant cochlin in the TM, absent in nonglaucomatous mice and healthy humans, may obstruct aqueous humor drainage and subsequently elevate increased intraocular pressure (Bhattacharya et al., 2005). The abnormal cochlin aggregates seen in some adult-onset glaucomas and the developmental upregulation of normal cochlin expression by RGCs seen in our study suggest that a source of mutant cochlin deposits may come from the RGCs themselves.

We also found RGC expression of CYP1B1, the gene linked to the GLC3A primary congenital glaucoma locus (Stoilov et al., 1997). Previous work has localized CYP1B1 expression to the anterior segment of the eye, and a CYP1B1 knock-out mouse demonstrates anterior segment abnormalities (Libby et al., 2003). CYP1B1 expression was also previously localized to early neural layer of the optic cup (Stoilov et al., 2004), but our data extend these observations to localize the protein to RGCs and further- 
more demonstrate that the message and protein are upregulated in RGCs through development.

\section{CYP1B1 enhances RGC survival}

We furthermore found that overexpressing CYP1B1 enhanced RGC survival, and knocking down CYP1B1 appeared to decrease RGC survival in vitro. CYP1B1 encodes a mono-oxygenase of the P450 superfamily and catalyzes the rate-limiting step in RA synthesis, oxidizing retinol to all-trans retinal (Chen et al., 2000). Interestingly, RA participates in cell proliferation and polarity establishment in early eye development (Sen et al., 2005) and may have antiapoptotic activity in the adult CNS by inhibiting JNK (c-Jun N-terminal protein kinase) activation (Ahn et al., 2005) or by inhibiting microglial expression of tumor necrosis factor- $\alpha$ (Dheen et al., 2005). The high embryonic expression of CYP1B1 observed in our study suggests that it may be an important source of RA for RGCs during embryonic and early postnatal development, especially considering that alcohol dehydrogenase 1 and 4, two potent embryonic synthesizers of RA, are not expressed in the eye during RGC development (Vonesch et al., 1994; Ang et al., 1996a,b). Thus, CYP1B1 mutations may potentially lead to congenital glaucoma by disrupting normal RA production in RGCs and subsequently impairing RGC survival during development or in the adult. It is interesting to hypothesize that CYP1B1 downregulation might also help to explain the timing of developmental cell death in RGCs.

We also found that RGCs express a number of genes found at loci linked to glaucoma. Our findings suggest a developmental function for these genes in RGCs and raise the hypothesis that cellautonomous expression of mutated or misexpressed glaucoma-linked genes including CYP1B1 or optineurin may directly induce susceptibility in RGCs to relatively elevated intraocular pressures, leading to dysfunction and cell death in RGCs. Any of these proteins may also decrease the ability of RGCs to regenerate their axons after injury in the optic nerve (Goldberg and Barres, 2000).

Axon injury does not recapitulate developmental gene expression

RGCs and other CNS neurons fail to regenerate their axons in the adult CNS environment. This failure is generally attributed to a glial environment rich in axon inhibitory molecules and poor in growth-promoting trophic factors or substrates. Blocking inhibitory glial signaling and adding exogenous trophic factors, however, generally only allows a small percentage of CNS neurons to regenerate and at a very slow rate, suggesting that regenerative failure may be intrinsic to adult CNS neurons. Consistent with
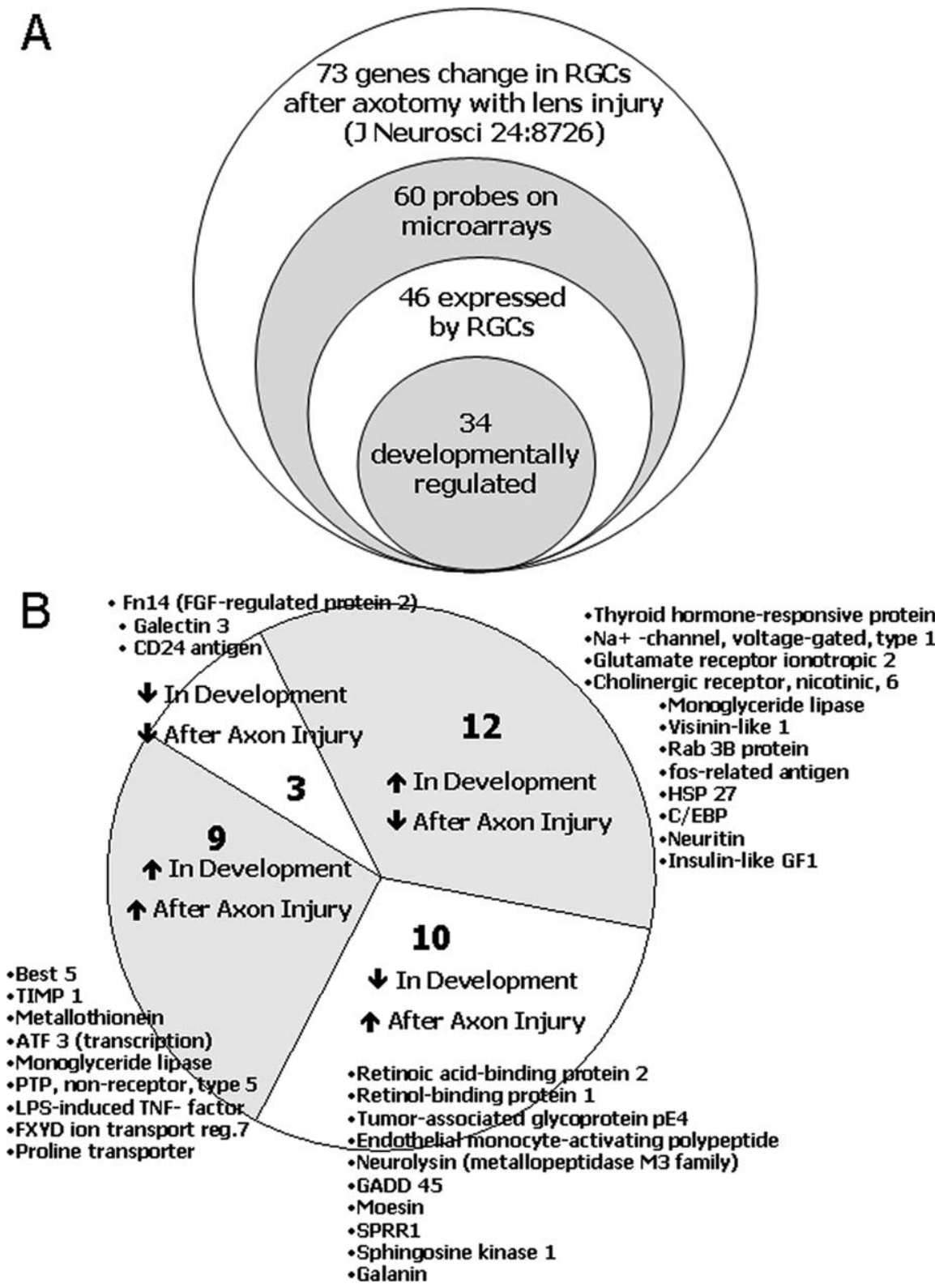

Figure 5. Genes expressed by RGCs that are regulated both during development and in regeneration. $\boldsymbol{A}$, Venn diagram demonstrating distribution of genes analyzed. $\boldsymbol{B}$, Pie chart demonstrating four classes of genes regulated up or down during development and up or down during regeneration.

this, we previously found that RGCs undergo a developmental loss of their intrinsic capacity for rapid axon growth, decreasing their rate of axon growth 10-fold in the first few days postnatally (Goldberg et al., 2002).

An important question is whether regenerative axon growth programs recapitulate developmental axon growth programs and whether such a recapitulation would enhance regenerative response (Filbin, 2006). Although RGCs decrease their intrinsic axon growth capacity through development, correlating with a failure of regenerative response in vivo, certain treatments such as Rho inactivation, CNTF plus cAMP application, and lens injury are able to enhance the regenerative response of RGCs in vivo (Leon et al., 2000; Cui et al., 2003; Yin et al., 2003, 2006; Fischer et al., 2004). It is not known whether such treatments change the intrinsic capacity of RGCs to rapidly grow axons, or enhance trophic signaling or overcome inhibitory signals in the environ- 
A
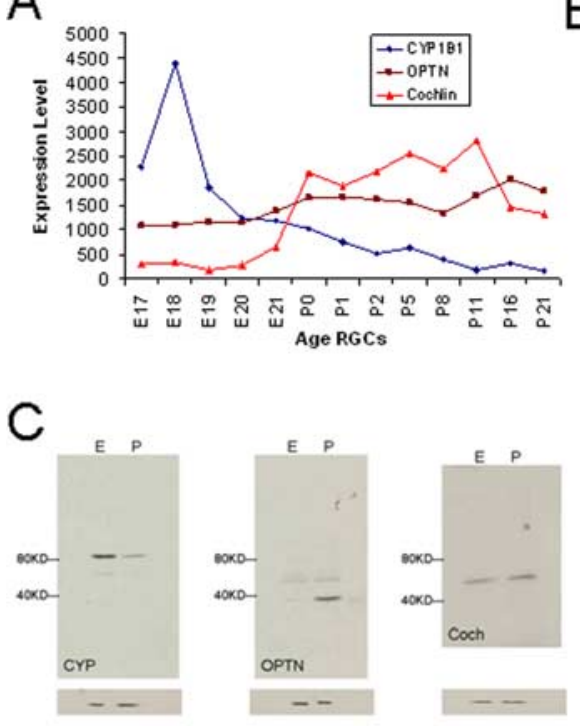

$\mathrm{D}$
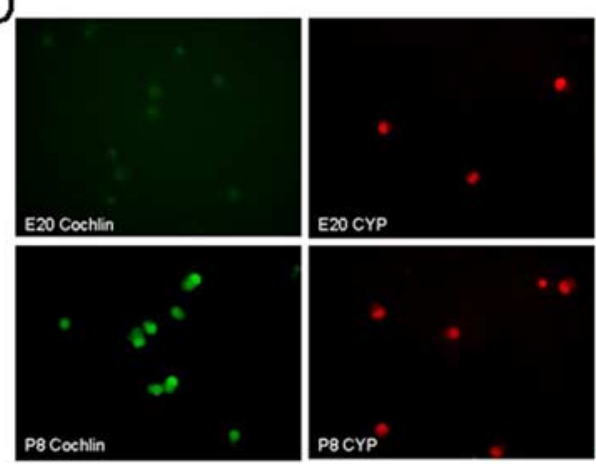

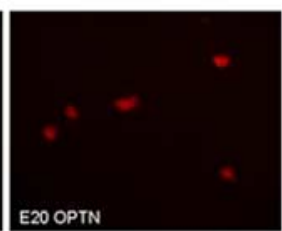

B

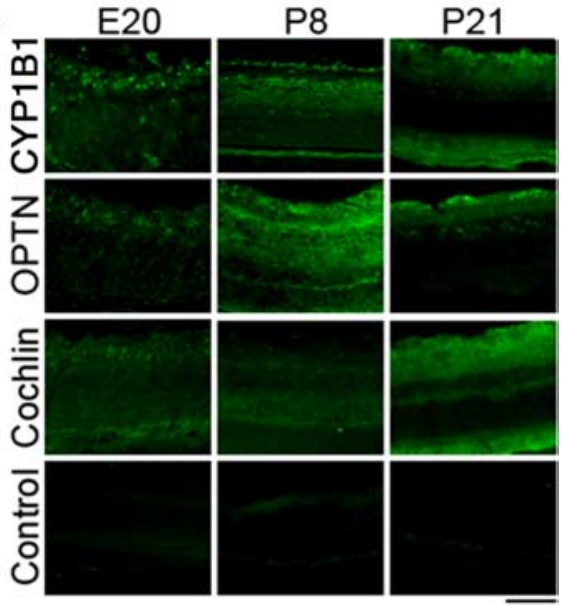

E20 OPTN

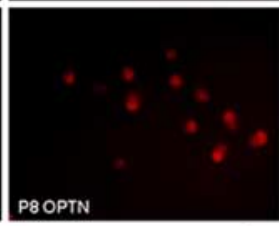

Figure 6. Expression of cochlin, CYP1B1 (CYP), and optineurin (OPTN) mRNA and protein in RGCs in vitro and in vivo. $\boldsymbol{A}$, Expression levels of the three mRNAs through RGC development from E17 to P21 from GeneChip data. $\boldsymbol{B}$, Immunoreactivity in the embryonic (E20), postnatal (P8), and early adult (P21) retina. Bright, punctuate staining in the ganglion cell layer (up in each panel) are particularly observed for CYP1B1 at E20 and for optineurin at P21. Cochlin also demonstrates an increase in expression level in the ganglion cell layer from E20 to P21, mimicking the mRNA data. C, Western blot analysis demonstrates cochlin, CYP1B1, and optineurin expression in lysates (15 $\mu \mathrm{g}$ of protein per lane) from purified E20 and P8 RGCs. High CYP1B1 protein level is detected embryonically, whereas increased optineurin and cochlin protein levels are higher postnatally. Blotting against actin (bottom row) demonstrates similar protein loading. D, Immunoreactivity in purified E20 and P8 RGCs after $24 \mathrm{~h}$ in culture. Mixed nuclear and cytoplasmic stainings were observed for cochlin (green) and optineurin (red). Perinuclear localization of endogenous CYP1B1 (red) is prominent at both ages. Scale bars, $40 \mu \mathrm{m}$.
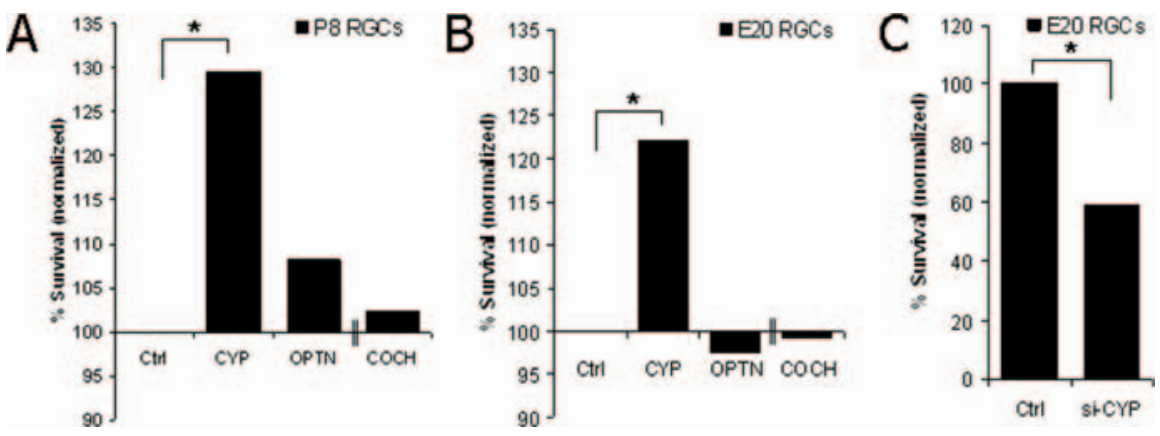

Figure 7. Effect of glaucoma-associated genes on $\mathrm{RGC}$ survival in vitro. $A, B$, Embryonic or postnatal $\mathrm{RGCs}$ as marked were transfected with plasmid controls (Ctrl) or CDNAs for CYP1B1 (CYP), optineurin (OPTN), and cochlin (COCH; performed in separate experiments and thus separated with double hash marks). RG( survival was measured $3 \mathrm{~d}$ later and normalized to control. Statistical analysis using SE of proportions yielded significant Z scores for CYP1B1 only $\left({ }^{*}\right)$. Representative experiments are shown. C, Embryonic RGCs transfected with an siRNA construct directed against CYP1B1 (si-CYP) demonstrated lower survival compared with control cultures.

ment. When we compared the genes that change more than threefold in adult RGCs in response to axotomy plus lens injury, which stimulates a subset of RGCs to successfully regenerate their axons in vitro and in vivo (Fischer et al., 2004), we found that, although there was a preference for inverse regulation between genes regulated during development and after injury, there were no easy correlations between the two. For example, galactin-3 has been shown to promote neurite outgrowth (Pesheva et al., 1998), is downregulated in RGC development consistent with the loss of axon growth ability of RGCs, and is upregulated after axotomy consistent with an attempted regenerative response (Fischer et al., 2004), but is actually downregulated in RGCs after lens injury plus axotomy compared with axotomy alone, despite the lens injury normally increasing RGCs regenerative success into the damaged optic nerve (Fischer et al., 2004). Thus, our data indicate that the genetic bases for regulating neurite outgrowth ability during development and regeneration after injury may share few similarities or involve separate mechanisms. These data generate a focused list of candidate genes, however, that may be shared between both situations, and such molecular hypotheses will likely have to be tested in vivo in injury models and during development to draw any strong conclusions.

In any case, our findings have important implications for understanding how retinal damage, and particularly the loss or injury of RGCs, can be repaired. The elaborate and complex program of gene expression changes that we identified during RGC development, together with our previous findings that RGCs irreversibly lose their capacity to rapidly extend axons, provide evidence that an intrinsic program of gene expression controls the elaborate timing and complexity of the developmental and morphological changes that an RGC undergoes during its development. A terminally differentiated RGC is not simply generated quickly in one step of gene expression changes from its progenitor cell, but rather it plays out a program of gene changes that extend over at least 3 weeks of its development. This complexity alone suggests that it is unlikely that, after injury, an RGC would suddenly reset to its embryonic state of gene expression and recapitulate this elaborate series of developmental events (such as axon growth, dendrite growth, synapse formation, target matching, synapse elimination, myelination, etc.). In fact, we found that injured RGCs do not reset or replay normal devel- 
opmental changes in RGC gene expression, and we found that similarity between the gene changes occurring during development and after injury was limited. Thus, to induce robust regeneration of RGCs, it may be necessary to either induce adult RGCs to revert to a newly generated transcriptional state, if this is possible, or perhaps to generate new RGCs from embryonic stem cells or retinal progenitor cells (Lamba et al., 2006).

\section{References}

Ahn JH, Kang HH, Kim YJ, Chung JW (2005) Anti-apoptotic role of retinoic acid in the inner ear of noise-exposed mice. Biochem Biophys Res Commun 335:485-490.

Ang HL, Deltour L, Zgombic-Knight M, Wagner MA, Duester G (1996a) Expression patterns of class I and class IV alcohol dehydrogenase genes in developing epithelia suggest a role for alcohol dehydrogenase in local retinoic acid synthesis. Alcohol Clin Exp Res 20:1050-1064.

Ang HL, Deltour L, Hayamizu TF, Zgombic-Knight M, Duester G (1996b) Retinoic acid synthesis in mouse embryos during gastrulation and craniofacial development linked to class IV alcohol dehydrogenase gene expression. J Biol Chem 271:9526-9534.

Arlotta P, Molyneaux BJ, Chen J, Inoue J, Kominami R, Macklis JD (2005) Neuronal subtype-specific genes that control corticospinal motor neuron development in vivo. Neuron 45:207-221.

Barres BA, Silverstein BE, Corey DP, Chun LL (1988) Immunological, morphological, and electrophysiological variation among retinal ganglion cells purified by panning. Neuron 1:791-803.

Bergman PB, Moravski CJ, Edmondson SR, Russo VC, Bach LA, WilkinsonBerka JL, Werther GA (2005) Expression of the IGF system in normal and diabetic transgenic (mRen-2)27 rat eye. Invest Ophthalmol Vis Sci 46:2708-2715.

Bhattacharya SK, Rockwood EJ, Smith SD, Bonilha VL, Crabb JS, Kuchtey RW, Robertson NG, Peachey NS, Morton CC, Crabb JW (2005) Proteomics reveal Cochlin deposits associated with glaucomatous trabecular meshwork. J Biol Chem 280:6080-6084.

Blackshaw S, Harpavat S, Trimarchi J, Cai L, Huang H, Kuo WP, Weber G, Lee K, Fraioli RE, Cho SH, Yung R, Asch E, Ohno-Machado L, Wong WH, Cepko CL (2004) Genomic analysis of mouse retinal development. PLoS Biol 2:E247.

Brunet JP, Tamayo P, Golub TR, Mesirov JP (2004) Metagenes and molecular pattern discovery using matrix factorization. Proc Natl Acad Sci USA 101:4164-4169.

Capone GT, Bendotti C, Oster-Granite ML, Coyle JT (1991) Developmental expression of the gene encoding growth-associated protein 43 (Gap43) in the brains of normal and aneuploid mice. J Neurosci Res 29:449-460.

Chen H, Howald WN, Juchau MR (2000) Biosynthesis of all-trans-retinoic acid from all-trans-retinol: catalysis of all-trans-retinol oxidation by human P-450 cytochromes. Drug Metab Dispos 28:315-322.

Chien CL, Liem RK (1995) The neuronal intermediate filament, alphainternexin is transiently expressed in amacrine cells in the developing mouse retina. Exp Eye Res 61:749-756.

Cui Q, Yip HK, Zhao RC, So KF, Harvey AR (2003) Intraocular elevation of cyclic AMP potentiates ciliary neurotrophic factor-induced regeneration of adult rat retinal ganglion cell axons. Mol Cell Neurosci 22:49-61.

De Marco N, Buono M, Troise F, Diez-Roux G (2006) Optineurin increases cell survival and translocates to the nucleus in a RAB8 dependant manner upon an apoptotic stimulus. J Biol Chem 281:16147-16156.

Dheen ST, Jun Y, Yan Z, Tay SS, Ling EA (2005) Retinoic acid inhibits expression of TNF-alpha and iNOS in activated rat microglia. Glia 50:21-31.

Doshi M, Marcus C, Bejjani BA, Edward DP (2006) Immunolocalization of CYP1B1 in normal, human, fetal and adult eyes. Exp Eye Res 82:24-32.

Ekstrom P, Johansson K (2003) Differentiation of ganglion cells and amacrine cells in the rat retina: correlation with expression of $\mathrm{HuC} / \mathrm{D}$ and GAP-43 proteins. Brain Res Dev Brain Res 145:1-8.

Escurat M, Djabali K, Gumpel M, Gros F, Portier MM (1990) Differential expression of two neuronal intermediate-filament proteins, peripherin and the low-molecular-mass neurofilament protein (NF-L), during the development of the rat. J Neurosci 10:764-784.

Faber PW, Barnes GT, Srinidhi J, Chen J, Gusella JF, MacDonald ME (1998) Huntingtin interacts with a family of WW domain proteins. Hum Mol Genet 7:1463-1474.
Farkas RH, Qian J, Goldberg JL, Quigley HA, Zack DJ (2004) Gene expression profiling of purified rat retinal ganglion cells. Invest Ophthalmol Vis Sci 45:2503-2513.

Filbin MT (2006) Recapitulate development to promote axonal regeneration: good or bad approach? Philos Trans R Soc Lond B Biol Sci 361:1565-1574.

Fischer D, Pavlidis M, Thanos S (2000) Cataractogenic lens injury prevents traumatic ganglion cell death and promotes axonal regeneration both in vivo and in culture. Invest Ophthalmol Vis Sci 41:3943-3954.

Fischer D, Petkova V, Thanos S, Benowitz LI (2004) Switching mature retinal ganglion cells to a robust growth state in vivo: gene expression and synergy with RhoA inactivation. J Neurosci 24:8726-8740.

Gauthier LR, Charrin BC, Borrell-Pages M, Dompierre JP, Rangone H, Cordelieres FP, De Mey J, MacDonald ME, Lessmann V, Humbert S, Saudou F (2004) Huntingtin controls neurotrophic support and survival of neurons by enhancing BDNF vesicular transport along microtubules. Cell 118:127-138.

Goldberg JL, Barres BA (2000) The relationship between neuronal survival and regeneration. Annu Rev Neurosci 23:579-612.

Goldberg JL, Klassen MP, Hua Y, Barres BA (2002) Amacrine-signaled loss of intrinsic axon growth ability by retinal ganglion cells. Science 296:1860-1864.

Grabs D, Bergmann M, Urban M, Post A, Gratzl M (1996) Rab3 proteins and SNAP-25, essential components of the exocytosis machinery in conventional synapses, are absent from ribbon synapses of the mouse retina. Eur J Neurosci 8:162-168.

Ivanov D, Dvoriantchikova G, Nathanson L, McKinnon SJ, Shestopalov VI (2006) Microarray analysis of gene expression in adult retinal ganglion cells. FEBS Lett 580:331-335.

Izumi S, Seki T, Shioda S, Zhou CJ, Arimura A, Koide R (2000) Ultrastructural localization of PACAP immunoreactivity in the rat retina. Ann NY Acad Sci 921:317-320.

Kawai F, Horiguchi M, Ichinose H, Ohkuma M, Isobe R, Miyachi E (2005) Suppression by an $\mathrm{h}$ current of spontaneous $\mathrm{Na}^{+}$action potentials in human cone and rod photoreceptors. Invest Ophthalmol Vis Sci 46:390-397.

Krueger-Naug AM, Emsley JG, Myers TL, Currie RW, Clarke DB (2002) Injury to retinal ganglion cells induces expression of the small heat shock protein Hsp27 in the rat visual system. Neuroscience 110:653-665.

Lamba DA, Karl MO, Ware CB, Reh TA (2006) Efficient generation of retinal progenitor cells from human embryonic stem cells. Proc Natl Acad Sci USA 103:12769-12774.

Lee CW, Park DJ, Lee KH, Kim CG, Rhee SG (1993) Purification, molecular cloning, and sequencing of phospholipase C- $\beta 4$. J Biol Chem 268:21318-21327.

Lee WH, Javedan S, Bondy CA (1992) Coordinate expression of insulin-like growth factor system components by neurons and neuroglia during retinal and cerebellar development. J Neurosci 12:4737-4744.

Leon S, Yin Y, Nguyen J, Irwin N, Benowitz LI (2000) Lens injury stimulates axon regeneration in the mature rat optic nerve. J Neurosci 20:4615-4626.

Libby RT, Smith RS, Savinova OV, Zabaleta A, Martin JE, Gonzalez FJ, John SW (2003) Modification of ocular defects in mouse developmental glaucoma models by tyrosinase. Science 299:1578-1581.

Lobo MK, Karsten SL, Gray M, Geschwind DH, Yang XW (2006) FACSarray profiling of striatal projection neuron subtypes in juvenile and adult mouse brains. Nat Neurosci 9:443-452.

Lodge AP, Howard MR, McNamee CJ, Moss DJ (2000) Co-localisation, heterophilic interactions and regulated expression of IgLON family proteins in the chick nervous system. Brain Res Mol Brain Res 82:84-94.

McLaughlin T, Hindges R, O'Leary DD (2003) Regulation of axial patterning of the retina and its topographic mapping in the brain. Curr Opin Neurobiol 13:57-69.

Meyer-Franke A, Kaplan MR, Pfrieger FW, Barres BA (1995) Characterization of the signaling interactions that promote the survival and growth of developing retinal ganglion cells in culture. Neuron 15:805-819.

Nelson BR, Matsuhashi S, Lefcort F (2002) Restricted neural epidermal growth factor-like like 2 (NELL2) expression during muscle and neuronal differentiation. Mech Dev 119 [Suppl 1]:S11-S19.

Park CS, Gianotti C, Park R, Krishna G (1996) Neuronal isoform of nitric oxide synthase is expressed at low levels in human retina. Cell Mol Neurobiol 16:499-515. 
Pesheva P, Kuklinski S, Schmitz B, Probstmeier R (1998) Galectin-3 promotes neural cell adhesion and neurite growth. J Neurosci Res 54:639-654.

Rezaie T, Sarfarazi M (2005) Molecular cloning, genomic structure, and protein characterization of mouse optineurin. Genomics 85:131-138.

Rezaie T, Child A, Hitchings R, Brice G, Miller L, Coca-Prados M, Heon E, Krupin T, Ritch R, Kreutzer D, Crick RP, Sarfarazi M (2002) Adultonset primary open-angle glaucoma caused by mutations in optineurin. Science 295:1077-1079.

Rhee SD, Kim E, Yoon SK, Yang SD, Okumoto M, Han SS, Song CW (2004) Fine localization of $\mathrm{Nefl}$ and $\mathrm{Nef} 3$ and its exclusion as candidate gene for lens rupture 2(lr2). Exp Anim 53:295-301.

Robertson NG, Resendes BL, Lin JS, Lee C, Aster JC, Adams JC, Morton CC (2001) Inner ear localization of mRNA and protein products of $\mathrm{COCH}$, mutated in the sensorineural deafness and vestibular disorder, DFNA9. Hum Mol Genet 10:2493-2500.

Rodger J, Symonds AC, Springbett J, Shen WY, Bartlett CA, Rakoczy PE, Beazley LD, Dunlop SA (2005) Eph/ephrin expression in the adult rat visual system following localized retinal lesions: localized and transneuronal up-regulation in the retina and superior colliculus. Eur J Neurosci 22:1840-1852.

Ruiz-Ederra J, Garcia M, Hicks D, Vecino E (2004) Comparative study of the three neurofilament subunits within pig and human retinal ganglion cells. Mol Vis 10:83-92.

Sakamoto K, Liu C, Tosini G (2004) Classical photoreceptors regulate melanopsin mRNA levels in the rat retina. J Neurosci 24:9693-9697.
Sen J, Harpavat S, Peters MA, Cepko CL (2005) Retinoic acid regulates the expression of dorsoventral topographic guidance molecules in the chick retina. Development 132:5147-5159.

Stoilov I, Akarsu AN, Sarfarazi M (1997) Identification of three different truncating mutations in cytochrome P4501B1 (CYP1B1) as the principal cause of primary congenital glaucoma (Buphthalmos) in families linked to the GLC3A locus on chromosome 2p21. Hum Mol Genet 6:641-647.

Stoilov I, Rezaie T, Jansson I, Schenkman JB, Sarfarazi M (2004) Expression of cytochrome P4501b1 (Cyp1b1) during early murine development. Mol Vis 10:629-636.

Vazquez-Chona F, Song BK, Geisert Jr EE (2004) Temporal changes in gene expression after injury in the rat retina. Invest Ophthalmol Vis Sci 45:2737-2746.

Vonesch JL, Nakshatri H, Philippe M, Chambon P, Dolle P (1994) Stage and tissue-specific expression of the alcohol dehydrogenase 1 (Adh-1) gene during mouse development. Dev Dyn 199:199-213.

Whitlock NA, Lindsey K, Agarwal N, Crosson CE, Ma JX (2005) Heat shock protein 27 delays $\mathrm{Ca}^{2+}$-induced cell death in a caspase-dependent and -independent manner in rat retinal ganglion cells. Invest Ophthalmol Vis Sci 46:1085-1091.

Yin Y, Cui Q, Li Y, Irwin N, Fischer D, Harvey AR, Benowitz LI (2003) Macrophage-derived factors stimulate optic nerve regeneration. J Neurosci 23:2284-2293.

Yin Y, Henzl MT, Lorber B, Nakazawa T, Thomas TT, Jiang F, Langer R, Benowitz LI (2006) Oncomodulin is a macrophage-derived signal for axon regeneration in retinal ganglion cells. Nat Neurosci 9:843-852. 